\title{
As mulheres de Barbacena (MG) e as Sessões Chiques de cinema (anos de 1926 e 1927)
}

\section{RESUMO}

O objetivo deste artigo é investigar a presença das mulheres de Barbacena (MG) nas sessões de cinema que foram dedicadas especificamente ao público feminino, denominadas "Sessões Chiques", com ênfase nas programações que aconteceram no Cine-Theatro Leal, entre os anos de 1926 e 1927. Com o intuito de analisar os sentidos conferidos a essas programações, realizamos a análise de reportagens do impresso Cidade de Barbacena, da revista Nação Brasileira, de sinopses e fotografias dos filmes transmitidos. Concluímos que as "Sessões Chiques" se tornaram momentos em que as citadinas puderam vivenciar uma nova experiência, mas com destacado caráter instrutivo e moralizador em se tratando do conteúdo projetado. Ainda assim, constatamos que elas foram incentivadas a outras atividades proporcionadas pelo lugar e pelas tramas das fitas que envolviam, por exemplo, enlaces amorosos e práticas corporais a exemplo das desempenhadas pelas atrizes hollywoodianas nas telas e nas páginas de revistas especializadas.

PALAVRAS-CHAVE: Cinema; Mulher; Barbacena-MG
Igor Maciel da Silva

Universidade Federal de Juiz de Fora UFJF, Campus Governador Valadares,

Departamento de Educação Física Governador Valadares, Minas Gerais, Brasil professorigormaciel@gmail.com

https://orcid.org/0000-0002-6560-0475

Sarah Teixeira Soutto Mayor

Doutora em Estudos do Lazer Universidade Federal de Juiz de Fora UFJF, Campus Governador Valadares,

Departamento de Educação Física Governador Valadares, Minas Gerais, Brasil sarahsoutto@gmail.com https://orcid.org/0000-0003-1643-6223 


\title{
The women of Barbacena (MG - Brazil) and the Chic Sessions of cinema (years 1926 and
} 1927)

\begin{abstract}
The purpose of this article is to explore the women's attendance at the city of Barbacena (MG Brazil) on cinema sections whose were specially dedicated to the women public called "Chic Sessions" with emphase on scheduals that happened at the Cine-Theater Leal Between 1926 and 1927. With the intention to analyze the meanings conferred to these programmings. A analyses of reportages from the journal Cidade de Barbacena, of the magazine Nação Brasileira, the synopses and photographs of the broadcasted movies was made. The conclusion was that "Chic Sessions" became moments where the female citizens where able to experiment a new experience, but with a highlighted instructive and moralizing character when it cames to the projected content. However it was verified that they were encouraged to other activities provided by the local and by the plot from the movies that involved, for exemple loving bonds e bodily practices inspired by the ones performed by the Hollywood actresses on screens and on personalizaded magazines pages.
\end{abstract}

KEYWORDS: Cinema; Woman; Barbacena-MG

Las mujeres de Barbacena (MG - Brasil) y las Sesiones Chic de cine (años 1926 y 1927)

\section{RESUMEN}

El propósito de este artículo es investigar la presencia de mujeres de la ciudad de Barbacena (MG Brasil) en sesiones de cine que se dedicaron específicamente a la audiencia femenina, llamadas "Sesiones Chic", con énfasis en los programas que ocurrieron en el Cine-Theatro Leal, entre 1926 y 1927. Para analizar los significados de estos programas, realizamos el análisis de artículos de los periódicos Cidade de Barbacena y Nação Brasileira, de sinopsis y fotografías de las películas transmitidas. Concluimos que las "Sesiones Chic" se convirtieron en momentos en que las mujeres de la ciudad podían vivir una nueva experiencia, pero con un sobresaliente carácter instructivo y moralizante con respecto al contenido proyectado. Sin embargo, descubrimos que fueron estimuladas por otras actividades proporcionadas por el lugar y por las tramas de las películas que centraron, por ejemplo, en temas de citas amorosas y prácticas corporales como las realizadas por actrices de Hollywood en las pantallas y en las páginas de periódicos especializados.

PALABRAS-CLAVE: Cine; Mujer; Barbacena-MG 


\section{INTRODUÇÃO}

As primeiras décadas do século XX experimentaram a expansão e a vulgarização de formas de divertimento atreladas à nova sensibilidade que se gestava com os desdobramentos do que se convencionou denominar de Revolução Científico-Tecnológica. Para Sevcenko (1993, p. 81-82) esse momento, também denominado de Segunda Revolução Industrial, abarcou um processo de mudanças intensas experimentadas especialmente a partir da década de 1870 e resultou "numa imensa escalada do investimento capitalista, que cresceu em volume e amplitude” (idem, p.87). Uma de suas consequências pode ser considerada a gestação e a posterior consolidação de uma indústria do entretenimento alimentada pelas diversões vivenciadas no espaço público, em decorrência do novo ethos que destinava às ruas das cidades o lugar por excelência das experiências modernas, em contraposição à contida e intimista lógica colonial.

Como parte de um promissor mercado da diversão em expansão, o cinema pode ser reconhecido como um dos principais inventos da modernidade, ao combinar o uso de uma nova e espantosa tecnologia com a permissividade da excitação e a possibilidade de se viajar pelo mundo sem sair da poltrona (BERNARDET, 1996; SINGER, 2004). Em um momento histórico de fronteiras ainda rígidas, essa possibilidade tornou-se abrigo para o conhecimento de novos lugares, novos povos e novos costumes, permitindo a expansão das formas de sociabilidade. Assim, o cinema se destaca por ser "uma nova tecnologia de percepção, reprodução e representação; uma nova mercadoria cultural de produção e consumo de massa; um novo espaço de congregação social na esfera pública" (ABEL, 2004, p. 215).

Nas metrópoles brasileiras que competiam pela insígnia que o termo "moderno" conferia nos anos iniciais do século XX, a existência de salas de cinema era um caractere obrigatório. A primeira projeção de imagens em movimento no Brasil ocorreu no Rio de Janeiro, na tarde de 8 de julho de 1896, com uma programação restrita a jornalistas e poucos convidados (FERREIRA, 1986).

Já em Minas Gerais, o cinema surge com a inauguração do Theatro Juiz de Fora, em 23 de julho de 1897 (GALDINO, 1983). Nesse dia, foi abrigada uma companhia de variedades "vinda de exibição no Rio de Janeiro, [...] composta por um grupo de artistas que apresentava números musicais, teatrais e circenses e tinha o cinematógrafo como principal atração" (LINO, 2009, p. 92). Como entretenimento de prestígio no cotidiano juizforano, o cinema foi citado como a doença da moda no início do século XX (LINO, 2009).

Outras cidades do vasto interior das Minas Gerais experimentaram essa novidade nos anos iniciais do século XX, por meio de um processo de circulação cultural possibilitado por incontáveis 
frentes, fruto de uma realidade em que informações, conhecimentos, produtos e tecnologias iniciavam uma escalada de compartilhamento em massa. Um contexto de influências certamente menos impactado pela noviça capital Belo Horizonte ${ }^{1}$ do que por localidades mais longevas e mais desenvolvidas à época, como a já citada Juiz de Fora², e metrópoles como Rio de Janeiro (então capital do país) e São Paulo.

A cidade de Barbacena, localizada na região mineira da Serra da Mantiqueira e na microrregião do Campo das Vertentes, está distante cerca de $170 \mathrm{~km}$ de Belo Horizonte. A região foi elevada à cidade em 9 de março de 1840, e entre o final do século XIX e início do século XX, destacava-se especialmente pelas atividades agrícolas e industriais desenvolvidas em seus distritos, com exportação de produtos para a capital do país (RIBEIRO, 2012; SAVASSI, 1991). No início do século XX, a cidade abrigava várias opções de divertimento, tais como: circo, apresentações literárias, teatrais e musicais, carnaval, danças, futebol, exposição pastoril, escotismo, piquenique, ciclismo, patinação, corrida de cavalos, quermesses, concursos de beleza e elegância, sessões filmicas, footing ${ }^{3}$, festas religiosas, cívicas e escolares, entre outras práticas que foram sediadas nos seguintes lugares: residências, ruas, praças, jardins, bibliotecas, escolas, teatros, salas de cinema, campos de futebol, rinques, salões de dança, confeitarias, cafés, bilhares, velódromos, lojas de compras, restaurantes, bares, hotéis, parques de diversão, associações recreativas, esportivas, literárias, musicais, beneficentes, de classe e carnavalesca (SILVA, 2018).

Sobre as projeções fílmicas, o pioneirismo é atribuído ao empresário Carlos Leal, quando em 24 de fevereiro de 1901 apresentou o animatographo aos barbacenenses. O cinematographo chegou ao município em 1906 com Joseph Adams \& Co. e, em 1909, o primeiro estabelecimento foi inaugurado, o Theatro Cinema Mineiro, propriedade de Paulo Benedetti (GALDINO, 1980; ORLANDO, 2005).

As pesquisas existentes sobre a história do cinema em Barbacena se referem, maiormente, às atividades de italianos radicados na cidade, em que se destacam Paulo Benedetti, Orlando Piergentili, Aroldo Piacesi e sua esposa Ines Piacesi. Acrescenta-se a isso que Benedetti também desenvolveu a atividade de diretor de documentários, junto a um grupo heterogêneo que incluía sua

\footnotetext{
${ }^{1}$ Belo Horizonte foi inaugurada em 1897 como a nova capital de Minas Gerais, em substituição à antiga e colonial Ouro Preto. As primeiras projeções nessa cidade datam de julho de 1898 (GALDINO, 1983).

${ }^{2}$ Além das atividades de cinema desenvolvidas em Juiz de Fora (GOMES, 1997; SIRIMARCO, 2005; BARROS, 2008; LINO, 2009; LISBOA, 2017) e Belo Horizonte (GOMES, 1997; MARQUES, 2007; MARTINI, 2010; MOURA, 2010, SOUTTO MAYOR, 2017, BARROS, 2017; MOTA, 2018; ALVARENGA; CHAVES, 2019), citamos as cidades de Diamantina (OLIVEIRA, 2016), Montes Claros (ALVES, 2018), Varginha (LIMA, 2017), Cataguases (GOMES, 1974), Campanha, Pouso Alegre e Itajubá (NOGUEIRA JUNIOR, 2017; SAMPAIO, 2009).

${ }^{3}$ Prática de encontro comum em diversas regiões do Brasil em que homens e mulheres caminhavam pelas ruas, praças, portas de cinemas, cafés e igrejas a fim de paquerar (SILVA, 2002).
} 
mulher Antonieta, sua cunhada Rosina, o empresário e maestro Umberto Boratto, entre outras personalidades ${ }^{4}$.

Nesse momento inicial, as mulheres de Barbacena compareceram nas projeções fílmicas especialmente na posição de assistentes. Todavia, de maneira mais restrita, outras atividades foram desempenhadas por elas no espaço do cinema, como organização de sessões beneficentes, apresentação de concertos musicais, atuação e produção de filmes (SILVA, 2018), escrita de jornais e matérias especializadas no assunto (PIMENTA, 2007) e no atendimento ao público na função de garçonete.

Diante da constatação da existência de diferentes formas de participação das mulheres no cinema em Barbacena no início do século XX, neste artigo foi investigada a presença delas nas sessões que foram dedicadas exclusivamente ao público feminino, intituladas "Sessões Chiques", com especial atenção às que ocorreram entre os anos de 1926 e 1927, promovidas pelo Cine-Theatro Leal, na intenção de analisar os sentidos conferidos a esse programa. A escolha do estudo dessa programação se deu porque foi o evento cinematográfico dedicado às mulheres que aconteceu de modo mais organizado e recorrente até a década de 1930.

Para tanto, a metodologia empregada foi a análise documental. De acordo com Melo (2011, p. 77), “a ferramenta fundamental para o pesquisador que decide se dedicar à investigação histórica da diversão é o mesmo arcabouço teórico e metodológico que a disciplina história tem construído no decorrer do tempo". Por isso, são necessários alguns critérios como a mobilização e análise de fontes.

As fontes escolhidas foram: de modo principal o jornal Cidade de Barbacena, e de modo secundário, a revista Nação Brasileira, sinopses e fotografias dos filmes transmitidos à época. Os exemplares do jornal se encontram na Hemeroteca Histórica da Biblioteca Pública Estadual Luiz de Bessa, localizada na cidade de Belo Horizonte. Já os outros documentos encontram-se na Hemeroteca Digital da Biblioteca Nacional ${ }^{5}$ e na Plataforma Internet Movie Database (IMDb), que se trata de uma base de dados criada no ano de 1990 para sediar informações a respeito de filmes, músicas e programas de televisão de distintos anos ${ }^{6}$.

Segundo Autran (2010), a imprensa é "a melhor fonte de consulta sobre a produção [fílmica] exibida no Brasil nas primeiras décadas do século [XX]”' (AUTRAN, 2010, p. 123). Sendo assim, a seleção dos jornais desta pesquisa seguiu a sugestão de Barros (2020), para quem a constituição do

\footnotetext{
${ }^{4}$ As pesquisas encontradas que analisam ou citam aspectos da história do cinema de Barbacena são: Autran (2010); Galdino (1980); Galdino (1983); Orlando (2005); Barro (2017); Gomes (2008); Gomes (2011); Pimenta (2007); Ribeiro (2012); Pimenta (2015).

${ }^{5}$ Disponível em: http://acervo.bndigital.bn.br/sophia/index.html Acesso em 14 jul. 2020.

${ }^{6}$ Disponível em: https://www.imdb.com/ Acesso 12 jul. 2020.
} 
corpus documental deve se adequar a alguns critérios, como pertinência, suficiência, representatividade e homogeneidade. Desse modo, pelos motivos expostos a seguir se deve a escolha do jornal Cidade de Barbacena. Da pertinência, a imprensa é considerada fonte privilegiada para o estudo do cinema no início do século XX. Da suficiência, o impresso é considerado o jornal de maior circulação na cidade, entre 1898 e 1993 (SAVASSI, 1991; RESENDE, 2012), e está digitalizado em arquivo sem muitas lacunas na periodicidade. Da representatividade, é um jornal que apresentou vários aspectos da região que envolveram ensino, economia, política, infraestrutura e opções de entretenimento. Da homogeneidade, é um documento que produziu um discurso homogêneo sobre a vida citadina sem parecer ter a intenção de destacar somente um aspecto da municipalidade. Sendo assim, foram coletadas reportagens do impresso Cidade de Barbacena referentes aos anos de funcionamento do Cine-Theatro Leal, respectivamente o último quartel da década de 1920, e analisadas sobretudo as que se referiam a programação denominada Sessão Chic extraordinaria que aconteceu entre 1926 e 1927.

A consulta à revista Nação Brasileira se deu por se tratar de uma publicação da cidade do Rio de Janeiro-RJ, que divulgava informações variadas sobre diversos lugares do Brasil, incluindo práticas de entretenimento de Barbacena. Já as sinopses foram recrutadas porque no jornal estudado alguns resumos dos filmes não foram divulgados, constando apenas anúncios das programações e pequenas chamadas para as fitas. Por fim, as imagens selecionadas nos ajudaram nas análises do conteúdo dos filmes projetados, visto que são consideradas produtoras de informações assim como as demais fontes (BOCCATO; FUJITA, 2006).

\section{AS MULHERES BARBACENENSES E O CINEMA}

Até o ano de 1930, identificamos os seguintes estabelecimentos que projetavam filmes em Barbacena: Theatro Cinema Mineiro, Theatro Cinema Moderno, Cinema Barbacenense, Cinema Parisiense, Cinema Avenida, Cinema Phenix, Cinema São José, Cinema Central, Cine-Theatro Apollo, Cine-Theatro Leal, Cinema Odeon, Cine-Theatro Santa Thereza, Cinematographo Brasil e Cine Iris. Além desses espaços próprios localizamos pistas sobre a projeção no ambiente doméstico, por meio da compra do projetor Pathé Baby, vendido na Casa Renascença. Tratava-se de um aparelho de 9,5 mm produzido pela Pathé Brothers Company e era assim apresentado: “o cinema do lar, que funcciona com corrente eletrica de uma lampada ou com magneto destinado aos logares onde não ha electricidade"” (CASA RENASCENÇA, 1924, p. 86). Pode-se inferir que a quantidade

${ }^{7}$ No presente estudo a escrita original das reportagens foi mantida. 
expressiva de salas existentes na cidade interiorana e a comercialização do projetor doméstico são indicativos do sucesso alcançado pelo cinema em Barbacena no princípio do século XX.

Sobre o público frequentador existem pistas da presença de pessoas de diferentes classes sociais (CINE-THEATRO APOLLO, 1924, p. 91). Contudo, aqueles que compareceram nas programações fílmicas de modo majoritário eram oriundos das classes mais abastadas, haja vista a forma como as reportagens se referiram aos frequentadores, como portadores de distintos modos, indumentárias elegantes e distintivos de classe como o chapéu, indumentária característica de pessoas ricas. Esse público era comumente designado como indivíduos do "escol social”, o que denota seletividade visto que o termo significava o que se sobressai economicamente em uma sociedade, ou seja, a elite. Outro indício é a existência de programas destinados às pessoas endinheiradas, como a Sessão Elite, organizada pelo Cine Leal, "dedicada a mocidade barbacenense, com um programma attrahente e soberbamente bello" (CINE-LEAL, 1926, n. 2217, p. 2).

Muitos dos cinemas locais promoveram momentos dedicados exclusivamente às mulheres, as "Sessões Chiques", e o público feminino também era retratado como pertencente à elite da cidade. Conforme uma programação realizada em 1917 no Cinema Barbacenense:

o "Barbacenense" realisou terça-feira ultima mais uma bella sessão chic em que foi exhibido um admiravel film da Fox "A filha do Sertão", trabalho cinematographico posado pela encantadora June Caprice que esteve deliciosa na interpretação do mesmo film. A platéa do "Barbacenense" que era constituida pelo Escól da nossa sociedade regorgitava e era encantador o aspecto do elegante cinema da praça da Intendencia, com a presença de quase todo o bello sexo de Barbacena, a quem era dedicado a sessão (DIVERSÕES, 1917, n. 1344, p. 2).

O uso do termo "belo sexo" corrobora uma das representações de mulher que se almejava instaurar nesse marco temporal, a de que era necessário ser bonita (SANT’ANNA, 2014) e agregar em sua rotina atividades relacionadas especialmente ao lar, como cozinhar, costurar, cuidar do marido e da prole (MALUF; MOTT, 1998). Por isso, a vivência no espaço público e em práticas de entretenimento pelas mulheres sofria de ambivalências entre "o ser permitido" ou "o acontecer com restrições", devido ao entendimento de seu corpo como delicado e frágil e de intenções normativas, nem sempre explícitas, de se controlar seus comportamentos. Como exemplo, atividades esportivas que envolviam contato corporal e o uso de força física (como o futebol, algumas provas de atletismo e as lutas) sofriam desaprovações constantes por serem consideradas inadequadas em relação aos papéis que o sexo feminino estava apto para desempenhar (GOELLNER, 1999). 
Em Barbacena, muitas das sessões exclusivas para as mulheres ofereciam descontos na compra dos bilhetes ou concediam a entrada gratuita. Essa possibilidade de acesso acontecia de forma frequente, mas sem regra de vigência, como assinalado no seguinte anúncio:

o Cine-Theatro-Apollo, recém inaugurado em 12 de agosto de 1923, em seu terceiro dia de atividade, em 23 de agosto, agradecendo publicamente na imprensa a simpatia recebida pelos citadinos, pediu para tornar público o convite de que daria naquele dia "entrada franca ás senhoras e senhorinhas" (CINE-THEATRO-APOLLO, 1923, n. 1921, p. 2).

Já em outros cinemas a concessão de entrada franqueada às mulheres aconteceu com periodicidade mais ampliada. Cita-se a Sessão Chic extraordinaria, oferecida às senhorinhas barbacenenses pelo Cine-Theatro Leal por mais de um ano, entre 21 de junho de 1926 e 10 de novembro de 1927.

O Cine Leal funcionava no prédio onde existia o Cine-Theatro Apollo. Este foi arrendado em 16 de julho de 1925 pela empresa $A$. Leal \& C., representada por Antonio Leal e Achilles Maia, empresários locais que já desenvolviam trabalhos com cinema em outra casa do gênero, o Cinema S. José.

O Cine Leal foi inaugurado em 19 de julho de 1925 e se destacava no cotidiano barbacenense devido ao fato de suas instalações serem continuamente reformadas e à diversidade de atividades que ofertava (PELOS CINEMAS, 1925, n. 2111, p. 1; PELOS CINEMAS, 1925, n. 2112, p. 2). A respeito das melhorias no recinto, essas incluíram a inauguração de uma varanda nobre com lotação para mais de cem pessoas (NO CINE-LEAL, 1926, n. 2221, p. 1), o ajuste das músicas com o enredo do filme assistido, dado que anteriormente era comum a falta de sincronicidade da orquestra com os temas das cenas, entre outras mudanças (PELOS CINEMAS, 1927, n. 2264, p. 1). Essa empresa pareceu estar preocupada em se adequar aos padrões de excelência comercial cinematográfica da época, pois se associou à Sociedade dos Grandes Exhibidores Cinematographicos, o que a colocou no circuito exibidor que incluía títulos que eram passados em cinemas do Rio de Janeiro, como "Capitolo, Imperio, Rialto e Casino" (O CINE-LEAL..., 1927, n. 2301, p. 1).

O jornal Cidade de Barbacena anunciou a data da inauguração da Sessão Chic extraordinaria do Cine Leal, todavia, a sua última atividade não foi divulgada. Cita-se o dia 10 de novembro de 1927 como o que sediou o final da Sessão, pois a última informação identificada sobre esse evento foi o convite divulgado dia 9 de novembro para a programação do dia seguinte (CINE LEAL, 1927, n. 2344, p. 3). Acreditamos que esse programa foi revogado, possivelmente, porque Achilles Maia teve sua parte na empresa comprada por Antonio Leal, que desde 30 de outubro de 
1927 passou a ser o único proprietário do cinema (CINE LEAL, 1927, n. 2342, p. 2). Inferimos que a Sessão Chic foi extinta logo em seguida ao rompimento dos sócios.

A Sessão Chic extraordinaria foi marcada inicialmente para as segundas-feiras, sendo posteriormente transferida para as terças. Mais tarde, teve a sua programação fixada nas quintas-feiras. A primeira Sessão Chic do Cine Leal contou com projeção de filme, de seriado e de um cinejornal com notícias de diversos lugares do mundo, o Fox Jornal. No seu convite foi assim divulgado:

[...] A partir de amanhã, todas as segundas-feiras, haverá uma $<<$ Sessão Chic extraordinaria $>>$, com programma escolhido a capricho, e para a qual a Empresa Maia \& Leal distribuirá entrada gratuita a todas as senhorinhas. E assim, amanhã, será exhibido o bello film - Porque as esposas tornam a casar, além de o seriado Nas garras do Hindú e o interessante - Fox Jornal. Certo, será muito concorrida a sessão de amanhã, que, como se vê, consta de escollidas pelliculas (CINE LEAL, 1926, n. 2204, p. 3).

A existência de programações como esta nos conduz a três principais reflexões que serão explicitadas a seguir: 1) A realização dessas sessões poderia ser um convite para as mulheres vivenciarem novas experiências de diversão de modo permitido pela sociedade. 2) Devido ao caráter educativo do cinema, as sessões dedicadas a elas podem ter almejado influenciar as sensibilidades das citadinas para funções sociais atribuídas às mulheres naquele contexto. 3) Esse tipo de programação poderia possibilitar encontros amorosos, o que fez do cinema um espaço para a vivência de distintas sociabilidades.

A última consideração corrobora o estudo de Vieira (2011), que indica que os homens também frequentavam sessões destinadas às mulheres, a exemplo da Sessão das Moças, organizada no Cine Ritz em Florianópolis (SC), entre os anos 1943 e 1962. Além de ambos os sexos se entreterem com os filmes, outras formas de sociabilidade relacionadas ao cinema foram usuais, como o footing.

Identificamos que o footing aconteceu na porta do Cine Leal nos dias da Sessão Chic, visto que no pedido publicado na imprensa para que o público frequentador dispusesse de melhores modos durante as projeções, também foi comentado que a polícia deveria intervir na entrada do cine-teatro, posto que existiam menores de idade que atrapalhavam ofooting das pessoas presentes (PELOS CINEMAS, 1926, n. 2251, p. 2).

Mesmo que o footing tenha sido uma prática de encontro que não dependia do cinema para acontecer, em Barbacena ele se dava especialmente na Rua XV de Novembro, considerada o principal ponto do footing local e principal via da cidade que interligava as demais ruas onde estava a maioria das casas exibidoras da região (TERRA DE MOÇAS BONITAS!, 1929, n. 249, p. 1). 
Segundo Vieira (2011), os temas dos filmes projetados em Florianópolis faziam convite para os assistentes praticarem o footing, porque tinham o amor e o relacionamento como principal roteiro das tramas. Em Barbacena, acredita-se que tenha acontecido algo semelhante, pois esses temas também constituíram as programações cinematográficas em dias dedicados às citadinas.

Demais assuntos foram projetados nos cinemas barbacenenses, os quais estiveram presentes na intenção de tornar o lugar não somente um espaço para o divertimento, mas também uma oportunidade de educação, influência, imposição e apresentação de modos e sensibilidades. Citam-se temas esportivos, religiosidade católica, comportamento e propagação de notícias, por meio de cinejornais. Tal consideração corrobora os estudos de Bicalho (1992, p. 115), para quem "o cinema envolve a produção de signos e o signo é sempre um produto cultural".

No tocante aos filmes identificados nas sessões dedicadas às mulheres, percebemos que se tratavam de temáticas prevalentes em sessões comuns. Contudo, baseados na reflexão de que esse tipo de programação também objetivou educar as sensibilidades do sexo feminino, algumas elucubrações podem ser feitas a partir de títulos, sinopses e publicidades encontradas.

Sem a pretensão de citar todos os títulos da Sessão Chique do Cine Leal sobre essas temáticas, apresentamos alguns que consideramos mais sugestivos: $O$ anjo do lar, Porque as esposas tornam a casar, Mimi Milindrosa, Amor é isso, $O$ destino dos homens, Vamos nos casar, A mulher do outro, Mocidade em demasia, Mocidade sportiva, Eva no Throno, Flirt e Casamento, Esposas descontentes.

No convite para Esposas descontentes nota-se que essa era uma fita direcionada a homens e mulheres, assim como a presença de prescrições para a conduta das que desejavam se casar, pois deveriam se afastar de momentos de alegria e prazer caso almejassem estar moldadas ao matrimônio. Contudo, se a alegria e o prazer citados pela notícia se relacionam à participação das mulheres nas programações de divertimento, o cinema pareceu não estar na lista dos entretenimentos desaconselháveis à elas, visto que a fita em questão poderia instruí-las nessa escolha. De acordo com a notícia:

[...] Amanhã - Mais uma grandiosa $<<$ Sessão Chic $>>$ extraordinaria, com o belissimo film Diamond - ESPOSAS DESCONTENTES, em 7 partes, onde se demonstra que a mulher acostumada à alegria e ao prazer, difficilmente se amolda ao matrimonio. E' um film que merece ser visto pois interessa a todos (CINE-LEAL, 1926, n. 2214, p. 2).

Já os títulos Flirt e Casamento, Mimi Milindrosa e Eva no Throno divergem um pouco com a representação de mulher veiculada em Esposas descontentes, pois também privilegiaram a figura da mulher moderna e melindrosa. $\mathrm{O}$ adjetivo melindrosa caracterizava as mulheres que, 
especialmente na década de 1920, aderiram a novos cortes de cabelo, usavam indumentárias tubulares medidas até a altura dos joelhos, tecidos mais leves, beiradas com franjas costuradas e pequenos decotes que contrastavam com os excessos impostos pela costura do século anterior (VAQUINHAS, 2016). Rouge para realçar as maçãs do rosto, uso de cosméticos para tratar a pele e práticas desportivas para cuidar do corpo também faziam parte da identidade das melindrosas. Pelo fato de aderirem a cortes de cabelo que deixavam a nuca exposta, o que até então era algo que constituía a imagem masculina, foram denominadas também de cabelos à Joazinho; de Evas, em alusão à primeira mulher da história da humanidade segundo a religião católica, mas com a ressalva de que se tratava de uma nova Eva, pois diferente da primeira que dependeu do homem para existir, a segunda era independente e com atitudes similares às dos homens. Este último fato refletiu em mais um vocábulo que as definiu, o de garçonnes (SCHPUN, 1999; PINHEIRO, 2015). A respeito da última expressão, de acordo com Vaquinhas (2016),

ser garçonne implicava, no entanto, capacidade econômica e alguma instrução, correspondendo esse modelo sobretudo a uma minoria de mulheres urbanas, pertencentes a classe média ou média alta, com possibilidade de cuidar da aparência, de frequentar os lugares da moda, de ter acesso à cultura francesa ou de estar atenta a novidades americanas (VAQUINHAS, 2016, p. 357).

Em Flirt e Casamento (1924), a personagem Nellie Wayne perde o marido, Pendleton, para a amante, fato que a incentiva a correr atrás de seus sonhos e se tornar escritora e modelista na Europa. No contínuo da trama, mesmo que ela estivesse frente à oportunidade de se vingar da ex-amante de seu esposo que já o tinha largado e estava com outro homem, acaba deixando essa ideia de lado e volta para o marido Pendleton. Nesse filme, o casamento mostrou-se como liberdade e prisão, pois somente quando a protagonista foi traída que a mesma teve a possibilidade de se realizar profissionalmente. No contínuo da trama, Nellie Wayne teve a oportunidade de seduzir o atual companheiro da ex-amante do marido, contudo, preferiu deixar sua vingança de lado e retornar à sua relação matrimonial. Desse modo, a trama oscila entre a representação da seduzente melindrosa e da mulher que escolhe viver o matrimônio ${ }^{8}$.

Já em Mimi Melindrosa, torna-se perceptível que a protagonista Patricia Mansfiel, interpretada por Bebe Daniels, pertencia à classe alta e gozava de possibilidades que não perpassavam pelo matrimônio, mas sim pela educação intelectual e por atividades esportivas, como

${ }^{8}$ Sinopse disponível em: https://www.imdb.com/title/tt0015120/ Acesso em 20 jun. 2020. 
a sua participação em provas de atletismo e o contato com o atleta Charlie Paddock ${ }^{9}$. Conforme a sinopse:

A product of wealth and high society, Patricia Mansfield is sent to Colton College by her father, who hopes to eradicate her snobbish veneer. On the train, Pat meets Denis Adams, a prominent athlete who is working his way through school as coach of the girls' track team; he introduces her to track star Charlie Paddock. Through efforts to keep her associates in place, Pat sinks deeper into the mire of antagonism; her only friends are Harriet Porter and Knute Knudson, the Swedish janitor. Trying to escape from Knute's pet mouse, she passes Paddock like a streak of lightning. Joining the fast set, Pat is soon branded as the campus flirt; realizing her foolishness, she sets out to vindicate herself by joining the track team. Before a meet, Graham Stearns abducts Adams, and Pat, in rescuing him, is herself detained. Knute rescues her in time for the race, and, in a screaming finish with chasing policemen, Paddock saves the event by running the last lap ${ }^{10}$.

A partir da imagem que se encontra abaixo, de Charlie Paddok ao lado da protagonista Patricia Mansifiel, percebemos a expressão de ação do corpo de Charlie, ao passo que no de Patricia verificamos um corpo estático a incluir o olhar. Tal leitura corrobora as representações da figura do homem e da mulher por diferentes mídias no início do século XX, como o cinema e os impressos (GOELLNER, 1999; FIGUEIREDO, 2007). Todavia, mesmo que a protagonista se encontre assim, destaca-se o uso de roupas coladas ao corpo para a prática do exercício físico, assim como o cabelo e a maquiagem que a definem como uma melindrosa. Tais aspectos demonstram a representação ambígua de mulher nesse filme que destacou a mulher pueril, diminuta na nomeação Mimi, e a nova mulher definida por Milindrosa.

\footnotetext{
${ }^{9}$ Charley Padock (11 de agosto de 1900 - 21 de julho de 1943), natural do Texas (EUA) foi um velocista norte-americano de muitos recordes, por isso, apelidado de o "homem mais rápido do mundo". Participou de algumas edições dos Jogos Olímpicos Modernos, a citar 1920 e 1924, essa última projetada no filme Carruagens de Fogo (1981). Além de atleta desenvolveu trabalhos de escritor e ator. Morreu em um acidente de avião enquanto servia na Segunda Guerra Mundial. Informações disponíveis em: https://www.britannica.com/biography/Charley-Paddock Acesso em 13 jul. 2020.

${ }^{10}$ Tradução: Um produto da riqueza e da alta sociedade, Patricia Mansfield é enviada para o Colton College por seu pai, que espera erradicar seu verniz esnobe. No trem, Pat conhece Denis Adams, um atleta proeminente que está estudando como treinador do time feminino de atletismo; ele a apresenta ao ator Charlie Paddock. Por meio de esforços para manter seus associados no lugar, Pat afunda ainda mais na lama do antagonismo; seus únicos amigos são Harriet Porter e Knute Knudson, o zelador sueco. Tentando escapar do rato de estimação de Knute, ela passa por Paddock como um raio. Juntando-se ao grupo rápido, Pat logo é rotulada como o namoradora do campus; percebendo a sua tolice, ela se propõe a se vingar entrando para a equipe de atletismo. Antes de um encontro, Graham Stearns sequestra Adams e Pat, ao resgatá-lo, é ela mesma detida. Knute a resgata a tempo para a corrida e, em uma finalização estridente com a perseguição de policiais, Paddock salva o evento correndo a última volta. Disponível em: https://www.imdb.com/title/tt0016705/plotsummary?ref =tt_ov_pl Acesso em 18 jun. 2020.
} 
Figura 1: Charlie Paddock e Patricia Mansfiel em Mimi Milindrosa (1926)

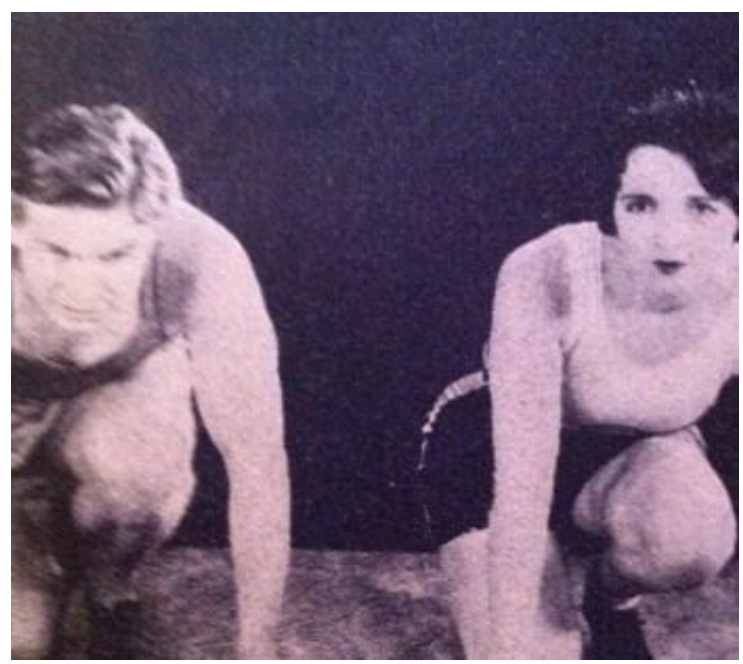

Fonte: https://www.imdb.com/title/tt0016705/mediaviewer/rm2320063232 Acesso em 20 de junho de 2020.

A respeito do filme Eva no Throno, não foi identificada a sua sinopse, apenas fotografias, as quais possibilitaram perceber a propagação da representação da melindrosa mais uma vez na Sessão Chic do Cine Leal. Como já apresentado, Eva era mais um sinônimo do perfil das garçonnes, e tal nome remete à mãe da humanidade que provou do pecado, e como sinônimo de melindrosa sugere o renascimento da mulher que, dessa vez, comportava-se de modo dissociado ou afim ao comportamento de homens, pois se divertia na vida noturna, fumava e tinha acesso a outros vícios. Atividades que sugerem a ascensão e o trono, como inscrito no título e nas imagens de uma mulher vestida com fardas, traje que nesse recorte temporal era de uso comum das autoridades masculinas. Todavia, assim como em Mimi Milindrosa (Figura 1), percebemos ambiguidade na representação de mulher, essa que por um lado se mostra contra os padrões de feminilidade por vestir uma farda, mas que por outro lado continua anatomicamente contida. Isso porque diferentemente de posturas como a continência, a tradicional saudação militar, Eva está com a feição tensa, desconfortável, como se a parte superior da farda que está acinturada a apertasse feito um corpete, objeto presente sobretudo na moda feminina das mulheres oitocentistas, ou seja, a mulher do passado; e a parte posterior, mesmo que confortável em seu corpo, representando liberdade, apresenta-se desajustada, como uma peça que não foi feita para ela. Fatos que simbolicamente poderiam tanto incentivar a mulher a ocupar um trono como desencorajá-la para esse lugar. 
Figura 2: Eva no Throno [Beverly of Graustark (1926)]

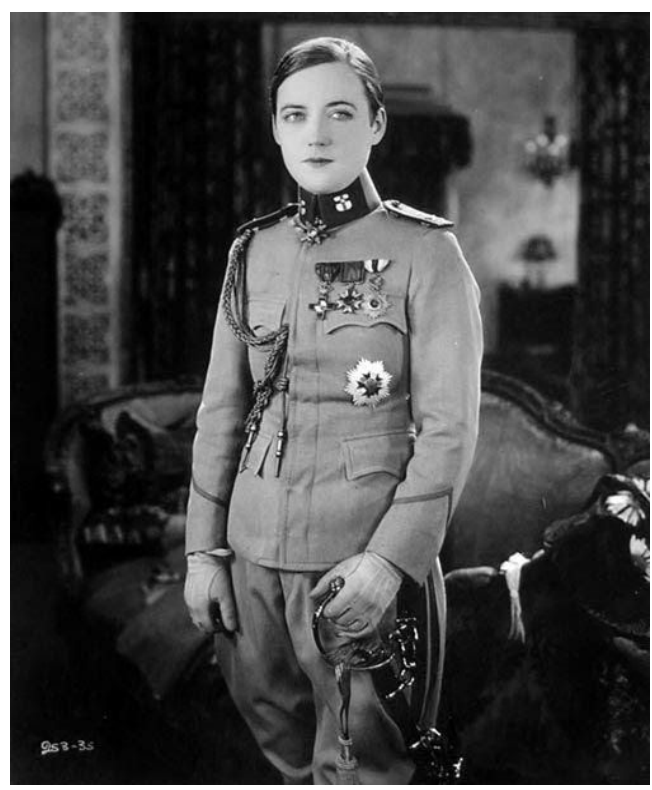

Fonte: https://www.imdb.com/title/tt0016646/mediaviewer/rm1521027840 Acesso em 18 jun. 2020.

Outros filmes existentes na programação da Sessão Chic do Cine Leal referenciavam o esporte nos títulos e nas tramas de forma destacada. O esporte, assim como o cinema, foi uma opção de divertimento moderno nessa centúria, vivenciado como prática e também presente nos roteiros fílmicos (MELO; VAZ, 2009). Na fita Mocidade Sportiva, projetada na Sessão Chic do Leal, em 1927 (CIDADE DE BARBACENA, 1927, n. 2274, p. 3), percebemos a disputa entre os estudantes Tom Brown e Bob McAndrew nas competições de futebol, remo, e também pela atenção de Mary Abbott, filha de um professor de Harvard ${ }^{11}$. A centralidade dada à ação de dois homens na disputa por uma mulher pode demonstrar as expectativas que eram esperadas aos diferentes sexos nesse marco temporal, visto que existiam recomendações para que os homens se envolvessem em práticas que exigiam maior esforço físico, como futebol, remo, algumas provas atléticas, entre outras (GOELLNER, 1999), contrastando com a participação da personagem Mary, que pareceu não se envolver com nenhuma prática da mocidade sportiva, mas sim esteve posta ao desejo do sexo oposto, apontando o lugar de espectadora da mulher, posição sugestivamente passiva no tocante ao esporte e às relações ${ }^{12}$. $\mathrm{O}$ cartaz da fita corrobora essa leitura, pois novamente identificamos homens em ação e mulheres inertes, a exemplo da análise feita sobre Mimi Milindrosa (Figura 1).

\footnotetext{
${ }^{11}$ Resumo disponível em: https://www.imdb.com/title/tt0016690/?ref_=ttpl_pl tt Acesso em 15 jul. 2020.

${ }^{12}$ Para conhecimento da relação das mulheres de Barbacena com práticas esportivas no início do século XX, consultar: Silva; Soutto Mayor, 2020; Silva; Rosa, 2020; Silva, 2020.
} 
Figura 3: Mocidade Sportiva [Browmn of Harvard (1926)]

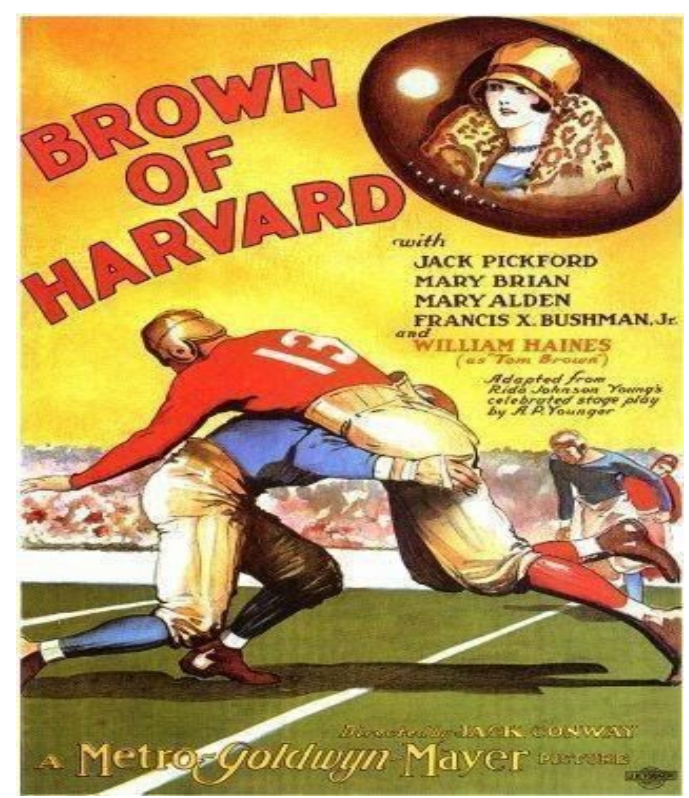

Fonte: https://www.imdb.com/title/tt0016690 Acesso em 15 jul2020.

A projeção de Esposas descontentes, Flirt e Casamento, Mimi Milindrosa, Eva no Throno e Mocidade Sportiva caracterizam a ambivalência de representações de estereótipos de mulheres projetadas em Barbacena no início do século XX, constando na mesma tela aspectos da esposa tradicional e da garota moderna.

A Sessão Chic extraordinaria do Cine Leal também contou com alguns brindes, como na programação de 26 de agosto de 1926, em que houve a distribuição gratuita de uma edição da revista Cinearte (CINE LEAL, 1926, n. 2223, p. 3), publicação carioca especializada em cinema que circulou entre 1926 e 1942 (FIGUEIREDO, 2007). A presença desse periódico como uma oferta no dia de uma sessão que tinha como foco as citadinas pode cooperar com o pensamento de que o cinema e os seus demais constituintes, por exemplo, o tema dos filmes e as revistas especializadas, podem ter sido peças complementares para reforçar a divulgação do ideário de mulher e dos modos que se queria fazer vigente. Em específico à Cinearte, a revista divulgava em suas páginas textos com caráter instrutivo, cooperava com a difusão do estereótipo da mulher hollywoodiana por meio da publicação de matérias que narravam a vida das atrizes, as práticas corporais que realizavam e propagava o ideal de beleza branca, magra e de orientação heterossexual (FIGUEIREDO, 2007). Percebe-se, assim, a existência de distintos veículos de divulgação de cinema em Barbacena, mas que pareceram ter objetivos parecidos. 


\section{CONSIDERAÇÕES FINAIS}

O cinema foi um dos principais divertimentos de Barbacena no início do século XX. Até o ano de 1930 identificou-se a existência de quatorze casas que se dedicaram à projeção de filmes na cidade com programações diárias. No espaço do cinema as mulheres participaram como assistentes das projeções, organizadoras de sessões beneficentes, intérpretes em concertos musicais, colunistas de jornais e autoras de matérias especializadas no assunto, na atuação e produção de filmes, e por fim, no atendimento ao público. Este artigo destacou as sessões fílmicas que foram organizadas especificamente para o sexo feminino, a fim de compreender os sentidos dessa programação.

Os programas dedicados às mulheres podem ser compreendidos como momentos em que as citadinas puderam vivenciar essa nova experiência de diversão de modo permitido, serem instruídas a partir do conteúdo projetado e também participar de encontros proporcionados por esse lugar e pelas temáticas das fitas.

A Sessão Chic extraordinaria do Cine-Theatro Leal foi o programa dedicado às mulheres que aconteceu de modo mais organizado e recorrente até a década de 1930. Nos temas dos filmes projetados especialmente nesta sessão, percebeu-se o prestígio de duas representações de mulher desse marco temporal que envolve a esposa e a melindrosa.

A guisa de conclusão, percebemos que o cinema, assim como outros dispositivos, como as revistas especializadas e cinejornais, mostraram-se como opções de entretenimento e ferramentas de educação das sensibilidades da época. No tocante às mulheres, acredita-se que o cinema serviu de inspiração para a permanência em antigos hábitos prescritos ao sexo feminino assim como para a vivência de novas experiências.

\section{REFERÊNCIAS}

ABEL, Richard. Os perigos da Pathé ou a americanização dos primórdios do cinema americano. In: CHARNEY, Leo; SCHWARTZ, Vanessa R. O cinema e a invenção da vida moderna. Tradução Regina Thompson. 2. ed. rev. São Paulo: Cosac Naify, 2004, p. 215-256.

ALVARENGA, Arnaldo Leite de; CHAVES, Elisângela. Arte e entretenimento: a dança teatral em Belo Horizonte (1897-1964). In: ROSA, Maria Cristina; DIAS, Cleber (org.). História do lazer nas Geraes. Belo Horizonte: Editora UFMG, 2019, p. 187-216.

ALVES, Rogério Othon Teixeira. "Da ponta dos trilhos ao centenário inventado": práticas modernas de divertimento em Montes Claros - MG (1926-1957). 2018. 267 f. Tese (doutorado) Escola de Educação Física, Fisioterapia e Terapia Ocupacional, Programa de Pós-graduação em Estudos do Lazer, Universidade Federal de Minas Gerais, Belo Horizonte - MG, 2018. 
AUTRAN, Arthur. A noção de "ciclo regional" na historiografia do cinema brasileiro. Revista Alceu - Revista de Comunicação, Cultura e Política, Pontifícia Universidade Católica do Rio de Janeiro/PUC-Rio, v. 10, n. 20, jan./jun. 2010, p. 116-125.

BARRO, Maximo. Participação italiana no cinema brasileiro. Editora SESI - Serviço Social da Indústria, 2017, 328 p.

BARROS, Cleyton Souza. Eletricidade em Juiz de Fora: Modernização por fios e trilhos (1889-1915). 2008. 159 f. Dissertação (mestrado) - Universidade Federal de Juiz de Fora, Programa de Pós- Graduação do Curso de História, Juiz de Fora - MG, 2008.

BARROS, José D'Assunção. A fonte histórica e seu lugar de produção. Editora Vozes: Petrópolis, 2020, 280 p.

BERNARDET, Jean-Claude. O que é cinema? São Paulo: Brasiliense, 1996.

BICALHO, Maria Fernanda Baptista. A arte da sedução: a representação da mulher no cinema mudo brasileiro. In: COSTA, Albertina de Oliveira; BRUSCHINI, Cristina. Entre a virtude e o pecado, Rio de Janeiro: Rosa dos Tempos; São Paulo: Fundação Carlos Chagas, 1992, p. 89-117.

BOCCATO, Vera Regina Casari; FUJITA, Mariângela Spotti Lopes. Discutindo a análise documental de fotografias: uma síntese bibliográfica. Cadernos bad: Revista da Associação portuguesa de bibliotecários, arquivistas e documentalistas, Lisboa, Portugal, 2006, p. 84-100.

CASA RENASCENÇA. Nação Brasileira, Rio de Janeiro, anno II, n. 15, nov. 1924, p. 86.

Disponível em:

http://memoria.bn.br/DOCREADER/cache/24143002248347/I0000834-20Alt=002416Lar=001672 LargOri=002593AltOri=003747.JPG Acesso em 14 fev. 2020.

CIDADE DE BARBACENA, Barbacena, 24 fev. 1927, n. 2274, p. 3.

CINE LEAL. Cidade de Barbacena, Barbacena, 1926, n. 2204, p. 3.

CINE-LEAL. Cidade de Barbacena, Barbacena, 1926, n. 2214, p. 2.

CINE-LEAL. Cidade de Barbacena, Barbacena, 1926, n. 2217, p. 2.

CINE LEAL. Cidade de Barbacena, Barbacena, 1926, n. 2223, p. 3.

CINE LEAL. Cidade de Barbacena, Barbacena, 1927, n. 2342, p. 2.

CINE LEAL. Cidade de Barbacena, Barbacena, 1927, n. 2344, p. 3.

CINE-THEATRO-APOLLO. Cidade de Barbacena, Barbacena, 1923, n. 1921, p. 2.

CINE-THEATRO APOLLO. Nação Brasileira, Rio de Janeiro, anno II, n. 15, nov. 1924, p. 91.

DIVERSÕES. Cidade de Barbacena, Barbacena, 1917, n. 1344, p. 2. 
FERREIRA, Paulo Roberto. Do kinetoscopio ao Omniographo. Revista Filme Cultura.

Embrafilme: Ministério da Cultura, n. 47, agosto, 1986, p. 14-21. Disponível em:

http://revista.cultura.gov.br/item/filme-cultura-n-47/ Acesso em 13 jul. 2020.

FIGUEIREDO, Priscila Kelly. Recônditos da Belleza: As práticas corporais em Cinearte e Scena Muda (1921-1941). 2007. 110 f. Dissertação (mestrado) - Faculdade de Educação, Universidade Estadual de Campinas, Campinas-SP, 2007.

GALDINO, Márcio da Rocha. Minas Gerais ensaio de filmografia, Prêmio Cidade de Belo Horizonte - Ensaio, Editora Comunicação, 1983, 430 p.

GALDINO, Márcio da Rocha. Paulo Benedetti - dossiê. In:ANDRADE, Rudá de; GALVÃO, Maria Rita; e outros. Cinema brasileiro: 8 estudos, Rio de Janeiro, MEC - EMBRAFILME - FUNARTE, 1980, p. 109-144.

GOELLNER, Silvana Vilodre. Bela, maternal e feminina: imagens da mulher na Revista Educação Physica. 1999. 180 f. Tese (Doutorado em Educação) - Faculdade de Educação, Universidade Estadual de Campinas, Campinas - SP, 1999.

GOMES, Paulo Augusto. Os italianos e o nascente cinema mineiro. Revista da imigração italiana em Minas Gerais - Ponte entre culturas, Belo Horizonte, 2011, p. 1-8.

GOMES, Paulo Augusto. Paulo Benedetti. In: GOMES, Paulo Augusto. Pioneiros do cinema em Minas Gerais, Belo Horizonte: Crisálida, 2008, p. 41-49.

GOMES, Paulo Augusto. 100 anos de cinema em Belo Horizonte. Varia História, Belo Horizonte, n. 18 , Set/97, p. 347-372.

GOMES, Paulo Emílio Salles. Humberto Mauro, Cataguases, Cinearte. São Paulo:

Perspectiva/Editora Universidade de São Paulo, 1974.

LIMA, Otávio Henrique Reis. Exibidores brasileiros: breve histórico de exibidores cinematográficos de Varginha (MG). 2017. 95 f. Trabalho de conclusão de curso em Cinema e Audiovisual - Instituto de Artes e Comunicação Social, Universidade Federal Fluminense, Niterói-RJ, 2017.

LINO, Sônia Cristina. Cinematographo: doença da moda. Revista do Arquivo Público Mineiro, Belo Horizonte, Dossiê, ano. 45, n. 1, jan./jun. 2009, p. 90-103.

LISBOA, Jakeline Duque de Moraes. O divertimento nos espaços associativos de imigrantes alemães e teuto-brasileiros em Juiz de Fora - MG: do último quartel do séc. XIX ao fím da II Guerra Mundial. 2017. 210 f. Tese (doutorado) - Escola de Educação Física, Fisioterapia e Terapia Ocupacional, Programa de Pós-graduação em Estudos do Lazer, Universidade Federal de Minas Gerais, Belo Horizonte - MG, 2017.

MALUF, Marina; MOTT, Maria Lúcia. Recônditos do mundo feminino. In: SEVCENKO, Nicolau. História da vida privada no Brasil. São Paulo: Companhia das Letras, 1998. v. 3. p. 368-421. 
MARQUES, Alexandre Pimenta. O registro inicial do documentário mineiro: Igino Bonfioli e Aristides Junqueira. 2007. 222 f. Dissertação (mestrado) - Escola de Belas Artes, Programa de Pós-Graduação em Artes, Universidade Federal de Minas Gerais, Belo Horizonte - MG, 2007.

MARTINI, Cristiane Oliveira Pisani. Festas, bailes, partidas e contradanças: as danças de sala do Bello Horizonte de 1897 a 1936. 2010. 162 f. Dissertação (mestrado) - Escola de Educação Física, Fisioterapia e Terapia Ocupacional, Programa de Pós-graduação em Estudos do Lazer, Universidade Federal de Minas Gerais, Belo Horizonte - MG, 2010.

MELO, Victor Andrade de. O lazer (ou a diversão) e os estudos históricos. In: ISAYAMA, Hélder Ferreira, SILVA, Silvio Ricardo da (Org.). Estudos do lazer: um panorama. Rio de Janeiro: Apicuri, 2011, 178 p.

MELO, Victor Andrade de; VAZ, Alexandre Fernadez. Cinema, corpo, boxe: reflexões sobre suas relações e a questão da construção da masculinidade. In: MELO, Victor Andrade de; DRUMOND, Maurício. Esporte e Cinema: novos olhares. Rio de Janeiro: Apicuri, 2009. p. 97-143.

MOTA, Andeza Gonsalez Rodrigues. Divirta-se quem puder: história e lazer em Belo Horizonte através da revista Semana Illustrada, 1927-1928. 2018. 75 f. Dissertação (mestrado) - Escola de Educação Física, Fisioterapia e Terapia Ocupacional, Programa de Pós-graduação em Estudos do Lazer, Universidade Federal de Minas Gerais, Belo Horizonte - MG, 2018.

MOURA, Rodrigo Caldeira Bagni. O amadorismo, o profissionalismo, os sururus e outras tramas: o futebol em Belo Horizonte nas décadas de 1920 e 1930. 2010. 162 f. Dissertação (mestrado) - Escola de Educação Física, Fisioterapia e Terapia Ocupacional, Programa de Pós-graduação em Estudos do Lazer, Universidade Federal de Minas Gerais, Belo Horizonte - MG, 2010 .

NO CINE-LEAL. Cidade de Barbacena, Barbacena, 18 ago. 1926, n. 2221, p. 1.

NOGUEIRA JUNIOR, José Martins. Uma história dos divertimentos do sul mineiro: Itajubá, Pouso Alegre e Campanha entre o final do século XIX e as primeiras décadas do século XX(1891-1930). 2017. 166 f. Dissertação (mestrado) - Escola de Educação Física, Fisioterapia e Terapia Ocupacional, Programa de Pós-graduação em Estudos do Lazer, Universidade Federal de Minas Gerais, Belo Horizonte - MG, 2017.

O CINE-LEAL e a Sociedade dos Grandes Exhibidores Cinematographicos. Cidade de Barbacena, Barbacena, 9 jun. 1927, n. 2301, p. 1.

OLIVEIRA, Renata Cristina Simões de. O teatro e algumas diversões em Diamantina: uma história registrada pela imprensa (1888-1915). 2016. 154 f. Dissertação (mestrado) - Escola de Educação Física, Fisioterapia e Terapia Ocupacional, Programa de Pós-graduação em Estudos do Lazer, Universidade Federal de Minas Gerais, Belo Horizonte - MG, 2016.

ORLANDO, José Antônio. A cidade dos Lunáticos. In: NAZARIO, Luiz (org.). A cidade imaginária, São Paulo: Perspectiva, 2005, p. 13-26.

PELOS CINEMAS. Cidade de Barbacena, Barbacena, 16 jul. 1925, n. 2111, p. 1.

PELOS CINEMAS. Cidade de Barbacena, Barbacena, 19 jul. 1925, n. 2112, p. 2. 
PELOS CINEMAS. Cidade de Barbacena, Barbacena, 1926, n. 2251, p. 2.

PELOS CINEMAS. Cidade de Barbacena, Barbacena, 20 jan. 1927, n. 2264, p. 1.

PIMENTA, Everton Fernando. Duas faces de uma mesma moeda: recepção e circulação do ideário fascista e integralista em Barbacena-MG através do casal Ines e Aroldo Piacesi, 1924-1945. 2015. 262 f. Dissertação (mestrado) - Programa de Pós-graduação em História, Universidade Federal de São João Del Rei - MG, 2015.

PIMENTA, Everton Fernando. Ines Piacesi, 1895, 1981: um ensaio biográfico. 2007. 110 f. Monografia (bacharelado em História) - Universidade Federal de Ouro Preto, Mariana -MG, 2007.

PINHEIRO, Larissa Brum Leite Gusmão. Garçonnizando-se: o fazer-se melindrosa.

Temporalidades: Revista Discente do Programa de Pós-Graduação em História da UFMG, v. 7, n. 2 (mai./ago. 2015), Belo Horizonte: Departamento de História, FAFICH/UFMG, 2015, p. 191-217.

RESENDE, Edna Maria. Do debate político à notícia: a imprensa periódica em Barbacena - séculos XIX e XX. Revista Mal-Estar e Sociedade, Barbacena, ano V, n.8, janeiro/ junho 2012, p.15-40.

RIBEIRO, José Silvério. História Econômica do Município de Barbacena v.1 (1889-1930) Tempos de Esperança/Silvério Ribeiro/ Barbacena: Gráfica e Editora Cidade de Barbacena, 2012, $704 \mathrm{p}$.

SAMPAIO, Carlos Leonardo Teixeira. A Igreja Católica e a transformação do espaço e do viver urbano de Pouso Alegre-MG (1936-45). 2009. 153 f. Dissertação (mestrado) - Programa de Pós-graduação em História Social, Pontifícia Universidade Católica de São Paulo, São Paulo-SP, 2009.

SANT'ANNA. Denise Bernuzzi de. História da beleza no Brasil. São Paulo: Editora Contexto, 2014. 205 p.

SAVASSI, Altair José. Barbacena 200 anos. Belo Horizonte: Editora Lemi S.A., 1991, v.1, 287 p.

SCHPUN, Mônica Raisa. Beleza em jogo: cultura física e comportamento em São Paulo nos anos 20. São Paulo: Boitempo Editorial/Editora SENAC, 1999. 164 p.

SEVCENKO, Nicolau. Transformação da linguagem e advento da cultura modernista do Brasil. Estudos Históricos, Rio de Janeiro, v. 6, n. 11, 1993, p. 78-88.

SINGER, Ben. Modernidade, hiperestímulo e o início do sensacionalismo popular. In: CHARNEY, Leo; SCHWARTZ, Vanessa R. O cinema e a invenção da vida moderna. Tradução Regina Thompson. 2. ed. rev. São Paulo: Cosac Naify, 2004. p. 95-123.

SILVA, Igor Maciel da. Rápida como os patins: a presença das mulheres na patinação em Barbacena-MG no início do século XX. Recorde: Revista de História do Esporte, Rio de Janeiro, v. 13, n. 1, jan./jun. 2020, p. 1-11. 
SILVA, Igor Maciel da; ROSA, Maria Cristina. Da participação de mulheres no futebol em Barbacena/MG nas três primeiras décadas do século XX. Revista Licere, Belo Horizonte, 2020, p. 114-142.

SILVA, Igor Maciel da; SOUTTO MAYOR, Sarah Teixeira. Mulheres no atletismo (Barbacena-MG, 1926): um estudo preliminar. Revista Caminhos da História, Montes Claros, Dossiê História do Esporte e das Práticas Corporais, v. 25, n. 1, jan./jun. 2020, p. 1-13.

SILVA, Igor Maciel da. Elas se divertem (Barbacena - MG, 1914 a 1931). 2018. 136 f. Dissertação (Mestrado) - Escola de Educação Física, Fisioterapia e Terapia Ocupacional, Universidade Federal de Minas Gerais, Belo Horizonte - MG, 2018.

SILVA, Sheyla Pinto da. Considerações sobre o relacionamento amoroso entre adolescentes. Cad. Cedes, Campinas, v. 22, n. 57, agosto/ 2002, p. 23-43.

SIRIMARCO, Martha. João Carriço - o amigo do povo. Juiz de Fora: Funalfa Edições, 2005.

SOUTTO MAYOR, Sarah Teixeira. O futebol na cidade de Belo Horizonte: amadorismo e profissionalismo nas décadas de 1930 e 1940. 2017. 359 f. Tese (Doutorado) - Escola de Educação Física, Fisioterapia e Terapia Ocupacional, Universidade Federal de Minas Gerais, Belo Horizonte MG, 2017.

TERRA DE MOÇAS BONITAS! Cidade de Barbacena, Barbacena, 1929, n. 249, p. 1.

VAQUINHAS, Irene. Cabelos à Joãozinho e melindrosas: uma nova imagem das mulheres nos anos 1920. In: JESUS, Isabel Henriques de; RIBEIRO, Paula Gomes; MIRA, Rita; DE CASTRO, Zília Osório. Falar de Mulheres dez anos depois. Centenário do Conselho Nacional das Mulheres Portuguesas, Húmus Ltda., 2016, p. 353-360.

VIEIRA, Alexandre Sardá. Sessão das moças: sociabilidade por escrito. Revista Cordis: Revista Eletrônica de História Social da Cidade, n. 6, jan./jun., 2011, p. 5-27.

\section{NOTAS DE AUTOR}

AGRADECIMENTOS - Não se aplica.

CONTRIBUIÇÃO DE AUTORIA - Não se aplica.

FINANCIAMENTO

Coordenação de Aperfeiçoamento de Pessoal de Nível Superior (CAPES).

CONSENTIMENTO DE USO DE IMAGEM - Não se aplica.

APROVAÇÃO DE COMITÊ DE ÉTICA EM PESQUISA - Não se aplica.

CONFLITO DE INTERESSES - Não há conflitos de interesses.

\section{LICENÇA DE USO}

Os autores cedem à Motrivivência - ISSN 2175-8042 os direitos exclusivos de primeira publicação, com o trabalho simultaneamente licenciado sob a Licença Creative Commons 
Attribution Non-Comercial ShareAlike (CC BY-NC SA) 4.0 International. Esta licença permite que terceiros remixem, adaptem e criem a partir do trabalho publicado, desde que para fins não comerciais, atribuindo o devido crédito de autoria e publicação inicial neste periódico desde que adotem a mesma licença, compartilhar igual. Os autores têm autorização para assumir contratos adicionais separadamente, para distribuição não exclusiva da versão do trabalho publicada neste periódico (ex.: publicar em repositório institucional, em site pessoal, publicar uma tradução, ou como capítulo de livro), com reconhecimento de autoria e publicação inicial neste periódico, desde que para fins não comerciais e compartilhar com a mesma licença.

\section{PUBLISHER}

Universidade Federal de Santa Catarina. Programa de Pós-Graduação em Educação Física. LaboMídia - Laboratório e Observatório da Mídia Esportiva. Publicado no Portal de Periódicos UFSC. As ideias expressadas neste artigo são de responsabilidade de seus autores, não representando, necessariamente, a opinião dos editores ou da universidade.

\section{EDITORES}

Mauricio Roberto da Silva, Giovani De Lorenzi Pires, Rogério Santos Pereira.

\section{EDITOR DE SEÇÃO}

Juliano Silveira

\section{REVISÃO DO MANUSCRITO E METADADOS}

João Caetano Prates Rocha; Keli Barreto Santos.

\section{HISTÓRICO}

Recebido em: 04 de agosto de 2020.

Aprovado em: 19 de novembro de 2020. 